MARKETING AND BRANDING
RESEARCH $\begin{gathered}\text { INDUSTRIAL } \\ \text { MANAGEMENT } \\ \text { INSTITUTE }\end{gathered}$

\title{
Slowness Saving the Day of Worldwide Travel and Tourism? Environmental and Sustainability Aspirations of Airline and Business Voyagers, Shared by International and Student Travelers as well as Religious Tourists
}

\author{
Konrad Gunesch \\ College of Media and Mass Communication, American University in the Emirates, Dubai, \\ United Arab Emirates
}

\begin{abstract}
Keywords: Sustainability, Triple Bottom Line, Slow Tourism, International Tourism, Airline Travel, Business Travel, Student Travel, Religious Tourism, Marketing and Branding Strategies
\end{abstract}

Correspondence: konrad.gunesch@aue.ae

\begin{abstract}
The paper's first part analyzes global tourism's core concerns and responsibilities in the new millennium, one of which is sustainability. Sustainability is shown to be made operational by the triple bottom line, which is analyzed as an internal managerial decision-making and planning tool as well as an external assessment and reporting framework. Key triple bottom line dimensions are presented together with economic, social, and environmental performance and impact measurements via a range of key indicators. The paper's second part evaluates the concept, forms, and contributions of slow travel and tourism to worldwide sustainability discussions, especially to forms of fast tourism. Slow tourism's meanings comprise sustainability and environmentalism. As an opposite to slow tourism modes, airline travel has conflicting solutions within the airline and tourism industries, their customer preferences, and the global business environment. Similarly, business travelers' motivations, decision-making, and beneficiaries have moved environmental and sustainability considerations up on their agendas. Multinational companies' corporate social responsibility endows them with a special role in branding and marketing their sustainability aspirations. Student and youth traveler numbers increase steadily, corresponding to their market relevance and diversity of motives. Finally, religious tourists occupy a central position in global travel considerations, which impacts pilgrimage locations and ecologies. The paper's third part shows how fast travel forms and industries can be inspired by slow tourism, especially when combining triple bottom line indicators, corporate social responsibility considerations, and slow travel and tourism philosophies and practices. This combined approach shows potential especially for global tourism's marketing and branding strategies.
\end{abstract}




\section{Part 1: Sustainability and the Triple Bottom Line in Worldwide Travel and Tourism Worldwide Travel and Tourism in the New Millennium}

According to the World Tourism Organization's "Tourism 2020 Vision", 11 key factors decisively influence global tourism including economical, demographical, and socioenvironmental factors. The World Tourism Organization has also announced 12 "megatrends" of worldwide tourism such as sustainable tourism based on a raised consciousness of environmental issues. Similarly, the literature (Dwyer et al., 2008) sees six "key drivers" for world tourism, namely economic (effects of globalization, labor demographics, and global wealth distribution); social (such as societal value changes); environmental (energy and natural resource preservation or global climate change); and basic human needs (global food provision or strategies for increasing cultural diversity).

\section{Sustainability in Worldwide Travel and Tourism}

"Sustainable development" was first officially, politically, and internationally defined on a high level in the 1987 "Brundtland Report by the World Commission on Environment and Development" as the compatibility of providing for today's generation without affecting the needs of future generations (see also Dwyer \& Edwards, 2013). In the wake of that report, several UN conferences reiterated and detailed that principle between 1992 and 2112 such as two famous conferences on environment and sustainable development in Rio de Janeiro twenty years apart, in 1992 and 2012 (see also De Lara \& Thöny, 2011). For tourism, a World Tourism Organization's 2005 guide for policy makers also conceptualized sustainability as a long-term balance between environmental, economic, and socio-cultural tourism development, focusing on using resources least incisively, respecting social and cultural traditions of host communities, and providing fair and future-oriented business dealings (United Nations Environment Program \& World Tourism Organization, 2005). While critical voices considered "sustainability" as an overall too unclear concept, besides being Westerncentric and favoring developed countries (Meyer, 2007), it has become both widely accepted and common practice in international politics, business practice, and tourism literature. Especially the latter has developed and detailed it into the operational framework of the "triple bottom line".

\section{Sustainability and the Triple Bottom Line}

Based on John Elkington's 1997 book "Cannibals with forks: The triple bottom line of $21^{\text {st }}$ century business", industries all over the world began considering not just economic, but also social and environmental influences in their operations. Tourism companies and business were considered especially valuable due to the size and impact of their industry (Gunesch, $2017 \mathrm{~g}$ ). The triple bottom line then adds to the economic bottom line or balance sheet the social and the environmental ones, with implications for both internal and external processes and procedures, evaluations and assessments, and planning and marketing operations (Dwyer \& Edwards, 2013; Tyrrell, Paris, \& Biaett, 2013). Each of these bottom lines or balance sheets is physically represented by key indicators on so-called report cards, containing a theoretically unlimited, but practically for each company and industry sector selected list of 
factors to be taken into consideration for its business dealings and activities (Murphy, 2012; Darcy, Cameron, \& Pegg, 2011).

\section{The Triple Bottom Line: Dimensions and Assessments}

Below are provided some selected examples for these key indicators on each report card and for each of the three dimensions, after a synthesis of many literature sources. Thus, for instance, the business report card would focus on information about the company's economic well-being, understood traditionally as the "single bottom line", namely turnover, revenue and profit, taxes, spending according to categories such as maintenance and repair, or visitor numbers and income. The social report card, then, would contain data and feedback such as on visitor or host community satisfaction, well-being, planning and suggestions. Finally, the environmental report card, in line with the mentioned principles of sustainability, would detail any and all relevant environmental or ecological impacts produced or caused by the tourism company on its surroundings, from natural resources such as air and water emissions and pollutions to influences on the host or neighboring communities and their residents, including the local flora and fauna, ecological habitats such as wildlife or reservoirs, up to measures to minimize or improve the corresponding conditions, such as wastage and pollution treatment, prevention or reparation measures, for example the installation of filters, the conduct of cleanup operations, or the arrangement of reparation and damage payments.

\section{Pros and Cons of Using the Triple Bottom Line}

The literature (Dwyer \& Edwards, 2013; Tyrrell et al., 2013) invokes several practical arguments against the triple bottom line, without denying its conceptual usefulness such as an unnecessary split of business considerations into three dimensions, the difficulty of finding suitable key indicators for each of the three dimensions, or the danger of having businesses pick and choose only the most favorable of those indicators within each dimensions, thereby, in the end report only on the positive qualities of their operations. Yet most criticism implies that the triple bottom line is (as of now) the most comprehensive and holistic framework for evaluating key indicators in the three most important dimensions that all tourism stakeholders face as a core concerns and responsibilities in the new millennium.

\section{Part 2: Environmental and Sustainability Aspirations of Slow Travel and Tourism The Development of Slow Travel}

Beginning in the last two decades of the $20^{\text {th }}$ century, the so-called "slow movements" in several areas of life (food and drink, leisure, artistic appreciation, professional management), entered the tourism industry as well, in the form and with the labels of "slow travel" or "slow tourism" (Dickinson \& Lumsdon, 2010). As these names suggest, the realization of such slow travel or tourism stood in contrast to the traditionally fast-paced forms of motion and travel, above all airplane travel. Included in the slower speed of external movement was the even more important aspect of internal attitude or character of the activity performed during such slow travel and tourism such as physically stopping and appreciating local sights, offers, salespeople, or participating the residents' local customs or speaking in their languages. Some 
even differentiate sharply between "slow travel" as the way and mode to reach the destination (foot, bicycle, train, etc.), and "slow tourism" as all the activities performed once at the destination and interacting with its sights, people, and places (Tiyce \& Wilson, 2012).

\section{Environmental Considerations of Slow Travel}

Within the environmental considerations of slow travel, there are some conceptual and practical differentiations, mainly within the academic literature, which is why they are treated here in summary form. For instance, while "green travel" is seen as centering on technical issues of environmental friendliness, for "slow travel" such environmental motives are relevant but not the chief motivation for the voyage. Correspondingly, some hold that slow tourism does not need additional or outstanding environmental awareness or actions, given that attitudes and experiences are about relating to inner self and outer surroundings. For others, slow tourism implies automatically environmental friendliness and consequently an environmental footprint as low as possible (Fullagar, Wilson, \& Markwell, 2012). Those who argue (or who accept) slow tourism's "low-to-no carbon footprint" philosophy further specify it with activities such as traveling to, staying at, and experiencing the destination in "slow modes", or planning fewer trips but making each one more extensive, interactive, and meaningful (Dickinson \& Lumsdon, 2010). Relatedly, while "hard slow travelers" are those for whom environmental care is the core of their travel, "soft slow travelers" see the environmental advantages as an added but not obligatory bonus (Dickinson \& Lumsdon, 2010; Fullagar, 2012).

As for specific slow travel forms, given the worldwide ubiquity and popularity of traveling by car, this mode is however contested by most as environmentally friendly, since it rarely justifies its low fuel-efficiency (Dickinson \& Lumsdon, 2010; Fullagar, 2012). By contrast, walking is the "classical" slow travel form, depending only on one's body, bringing the traveler into most direct and personal contact with people and places (Tiyce \& Wilson, 2012), and thus, especially cherished by "hard slow travelers" (Dickinson \& Lumsdon, 2010). Cycling, similarly low-carbon and surroundings-friendly, is seen as a low-technology but high-individualism statement, accruing health, social and even speed advantages (which highlights that "slow tourism" does not have to be of "pedestrian" speed). Its ecological value and reputation, compared to those upsides, is maybe the strongest one among all travel forms (Fullagar, 2012). Train travel, then, is often seen as the perfect combination of interactive and convenient travel (unlimited engagement with other travelers while having all-round vistas under full cover and protection) with considerable speed and distance covered. While some question the character of "slowness" at today's technologically possible high train speeds, few argue the environmental advantages of train travel. By comparison, bus and coach networks have the upside of greater route and destination flexibility, and hence seen as more adventurous and affordable, yet less spacious and comfortably (Dickinson \& Lumsdon, 2010).

\section{Predictions for the Development Slow Travel}

Slow travel is only hesitantly suggested to be a growth market. It tends to segment customers by travel mode, by environmental concern (hard or soft slow travelers), by travel distance (short- or medium-haul), by motivation (slowness as intrinsically or extrinsically sought), or 
by tour operator involvement (facilitation of booking, or controlling undesirable aspects such as weather exposure). The future of slow travel is predicted among these lines (see Dickinson and Lumsdon, 2013; Gunesch, 2017f): slow travel might continue as a small market alongside other forms of alternative tourism; establishes itself in the mainstream, especially as lowcarbon travel modes; or develop according to existing and provided overland infrastructures. Overall, hopes are for slow travel to establish itself among the various forms of "new tourism".

\section{Airline Travel's Environmental and Sustainability Aspirations}

For the last twenty years, the airline travel and tourism industry has progressively trying to reconcile environmental requirements and pressures with its goal of maximum passenger load and capacity. In the wake of the "Kyoto Protocol" of 1997, global climate change agreements and subsequent national implementations and regulations have produced the possibilities of either "cap-and-trade" options (meaning polluters above regulated limits have to pay for the privilege, while non-polluters or those remaining below those limits benefit financially), or "emission trade" permits (which allow the businesses within one industry to exchange such options directly among each other). Within the context of the mentioned lowering of companies' carbon footprints, this is pursued as "carbon offsetting" with the final goal of "carbon neutrality" (Daley \& Callum, 2011). Consequently, airports have begun to reorganize their inner workings and outer marketing operations. However, technical details remain contested, for instance who ultimately produces, hence owns, and thus ultimately is responsible for those emissions (Gunesch, 2017a). This complex interplay of interests illustrates the urgent need among the stakeholders to work together for technical, regulatory, competency, and marketing solutions (ranging from installations of filters over the levy of emission taxes to customer preferences of airlines, whether expressed as travel seats or stock market options) (Graham, 2011). Having read the signs on the wall, the global airline industry tries to pre-empt such problems by introducing progressive travel technology and operations, as with the widely publicized launch of the hitherto biggest commercial passenger plane in the world, the "Airbus 380", which comes with the environmental perk of being built largely of composite and renewable parts and materials (Lück, 2012).

\section{Business Travel's Environmental and Sustainability Aspirations}

Technological progress of groupware or collaborative software (application software designed to assist several people in achieving a common task) has increased the connection speed, media quality, interface advancements, and communicative sophistication of, for instance, video or virtual business conferences. This has led to traditional office and direct meetings to be increasingly replaced with virtual encounters, which in turn has considerably changed the ways resources are considered and invested in human workplace collaboration over distances of geographical boundaries, time zones, and linguistic differences. In the wake of this development, traditional physical business meetings have been reserved and relegated to highstakes deals or major players, or specialized professions such as sales. Overall, virtual travel has helped business travel to claim increased returns on investment (Stangel, 2014). This is even more the case for multinational companies in the realm of travel and tourism in today's 
ever more globalizing world, where direct meetings are now reserved mainly for affairs that require worldwide coordination and personalized communication (Sharma, 2004). Finally, companies and business on all levels find themselves under heightened scrutiny on the part of their stakeholders (private or public) to be considerate and transparent about their environmental impact or carbon footprint. As a consequence, the more environmentally or ecologically incisive a company's operations, the more it will gravitate towards adopting appropriate considerations (Gunesch, 2017b). These considerations can now be suitably and clearly expressed via the mentioned dimensions and categories of the triple bottom line.

\section{Travelers, Destinations and Hosts as Stakeholders of International Tourism}

Stakeholders in business terms are all those affected by a company's activities and actions, which for global tourism companies can be public as well as private people or groups such as tourists, tourist organizations, or travel corporation (Gunesch, 2017c; Hall \& Brown, 2010). Among these stakeholders, residents are used to having their needs and wants met before any other stakeholder group; following this, host communities' development and growth are directly helped by tourists' purchases of goods and services, from craft and transportation to activities and accommodation. This puts many developing tourist nations in a dilemma between needing the dividends out of their local tourism industry while at the same time loathing the social or ecological degradation of their surroundings, which in turn might push them to adopt collective measures of prevention or repair; while individually they might react with hostility, xenophobia, or worse, and unsavory business models that might give profit to a few but harm the entire tourism industry (Brown, 2011; Sharma, 2004). On the other hand, communities realize that the same potentially eroding tourism can also benefit them when it makes both hosts and visitors more aware or protective of their shared natural or created heritage. Therefore, the greatest danger to the travel and tourism industry in developing nations remain the same as those for the entire country, especially conflicts and wars directly destroying destinations or dissuading visitors, besides natural catastrophes such as floods, storms, or epidemics (Goeldner \& Ritchie, 2014; Moutinho, Ballantyne, \& Rate, 2011).

\section{Multinational or Transnational Corporations as Stakeholders of Global Tourism}

MNC or TNCs (Transnational Corporations) find themselves acutely in the dilemma between fiscal profit pressures in the sense of the classical, economical, first bottom line, and the theoretically well-established concept of corporate social responsibility (CSR). While CSR tries to reconcile profit and social responsibility, which would benefit the earlier mentioned stakeholders of destinations and hosts, many tourism companies claim that especially their sector puts them under competitive pressures that counteract many of their endeavors towards the second and third bottom lines, that is, their social and environmental efforts (Brown, 2011; Hall \& Brown, 2010). It is here where good branding and marketing seem to be of particular importance and value for the individual tourism company, the entire tourism industry, all stakeholders of international travel and tourism, and for the social and ecological balance of the world at large. Given the economic influence and therefore potential political leverage of these global giants, their stakeholder position is thus particularly relevant for marketing and branding strategies; it is precisely multinational companies' complex and 
contentious position between firstly the three bottom lines (with a potential conflict between the first bottom line on the one hand and the second and third one on the other hand), secondly their corporate social responsibility (with another potential conflict between their corporate profit interests and their social responsibilities), and the interplay between the triple bottom line and corporate social responsibility (with potential further conflicts, but also mutual reinforcements and benefits between these two principles).

\section{Student and Youth Travelers as Stakeholders of International Travel and Tourism}

Students form a special subgroup of global travel and tourism stakeholders due to their financial and philosophical outlook impact triple bottom line considerations. Compared to other tourist segments, students travel more times but for less time, in more exploratory spirit and greater expense in relation to their income, plan and buy more online travel products; following this, they are less scared of man-made or natural disasters, are more engaging with the local populations, innovative in technological or social aspects of travel, and with these characteristics typify environmentally aware and ecologically sensitive travel (Gunesch, 2017d). Altogether, for them travel is a lifestyle statement and inalienable and inextricable part of their personal and group identities, which they see as part and parcel of their missions of lifelong learning and experience, encounter with different countries and cultures, private and professional development, and idealistically contribute to the construction of their worldly and spiritual values (Richards, 2008). Altogether, student and youth travel is seen as one of the socially and environmentally most beneficial forms and representations of global travel and tourism, ranging from the realms of education and culture over those of politics and economy into those of ecology and environment (Page, 2009; Richards, 2008). Hence tourism companies and providers which focus on catering to this market segment are arguably targeting the second and third bottom line in exemplary ways.

\section{Religious Travelers as Stakeholders of International Travel and Tourism}

Religious tourism and pilgrimage sites were often conceived and constructed with spiritual motivations, making for instance remote mountains frequent and preferred locations, as such embodying mankind's search for higher aspirations, or divine order and balance on earth. This constellation, however, carries with it particular conflicts between stakeholder interests, when for instance economic and ecological pursuits and interests corrode the spiritual value for which those locations and sights were erected in the first place (Gunesch, 2017e). China is well-known for many such locations, as for instance Taoist and Buddhist beliefs both revere the Four Sacred Mountains of Emei, Jihua, Putuo, and Wutai as a bodhimandas, meaning enlightened places for the residence of bodhisattvas or enlightened beings. As another example, the $5^{\text {th }}$ to $14^{\text {th }}$ century murals in northwest China's Caves of the Thousand Buddhas, spreading over 577 grottos and 45,000 square meters, suffer continuous damage from tourists who raise their internal humidity and temperature ( $\mathrm{Mu}$ et al., 2007). Thus, many Chinese tourist destinations have come to prohibit typical yet harmful tourist activities such as littering, engraving walls, cooking and camping in the open environments, felling trees, or celebrating with fireworks, while for example Middle Eastern monasteries such as Saint Catherine's at Mount Sinai in Egypt enjoy international collaboration in measures of 
environmental awareness raising, education, and protection ( $\mathrm{Mu}$ et al., 2007; Olsen \& Timothy, 2006). Finally, there are even movements supporting tourism for world peace and development with their own list of requirements for travelers and destinations, ranging from all-round educational measures, preserving and protective measures for cultural heritage and on-site treasures, over engagement and support for residents including developmental assistance, and confronting any harmful acts and activities, up to endorsing exclusively those tourism companies and business which subscribe to the same code of ethics (Haessly, 2010).

\section{Part 3: Uniting Sustainability, the Triple Bottom Line, and Slow Tourism}

We have seen that the triple bottom line can boost and foster a tourism company on several levels, ranging from theoretical foundations such as clear definitions of what sustainability is supposed to mean, over practice considerations, strategy assistance, clarity for all the stakeholders involved, raising of the overall company value, improvement of quality levels and benchmarks, internal relationships with employees and staff, outside and market respectability and standing, up to Overall, advantages for the tourist destination.

If we combine these triple bottom line advantages and insights with those of slow travel and tourism, an interesting picture takes shape which makes ideological and practical coursechanges of "fast travel" so interesting, insightful, and valuable for worldwide travel and tourism. In simple terms, if fast travel changes the way they do business and find it recommendable to "slow down", then they seem to be on to something that could serve as a guide for the entire travel and tourism industry.

As a stakeholder group that straddles both forms of travel, youth and student travelers might (due to their age, dynamism, and possible future career aspirations) be familiar or even strive for environmentally or socially taxing fast travel forms (such as airline or business travel), while at the same time embodying (due to financial restrictions, but also inspired by deeper insight) more socially and environmentally-friendly travel forms (such as low-to-no carbon emissions and ecological footprints).

\section{Recommendations for Global Travel and Tourism's Marketing and Branding Strategies}

All these suggest that the combination of triple bottom line and slow travel yields insights and practical advantages for worldwide travel and tourism on several levels: First, these two concepts might be able to form a "double pack" of sustainability which each of them alone could not perform as effectively. For instance, the forms of slow travel can inspire those of fast travel simply with their existence and increasing realization by ever higher numbers of tourists. Following this, we can now add to these current trends the detailed substantiation, evaluation, and practical argument in favor of triple bottom line company reporting, business enhancement, marketing and reputation improvements and global sustainability and environmental contributions.

Second, triple bottom line and slow travel could mutually influence and benefit from each other: For example, both fast and slow travel forms and companies could seek to enhance their sustainability understanding and operations not only via committed implementations and 
applications of the triple bottom line, but also via conscious collaborations and efforts to exchange and share their insights and progresses.

Third, the benefits of combined or synthesized triple bottom line and slow travel reflections and actions could benefit even other industries, either inside or outside of worldwide travel and tourism, as long as these industries share with slow tourism the wish to consider sustainability as one of their operational criteria. As an example of industries within travel and tourism, tourist resorts (even if offering mainly localized activities on their premises) can now consider slow activities and their ecological, economic, and social impacts on their guests as well as the surrounding host community. As an example of industries outside (but still related) to global tourism, the entertainment industry (for instance sports, film or casino tourism) can equally incorporate slow or at least sustainable variants into their offerings (as is increasingly done by recent large-scale and highly diversified entertainment complexes which offer many amenities under one roof).

Finally, as we have seen when investigating multinational or transnational corporations in the global travel and tourism sector, the sustainability considerations, the triple bottom line, and slow tourism philosophies can even form a "triple pack" of mutually beneficial business concepts and practical results. Instead of seeing the second and third bottom line as impeding the first bottom line's profit interests or seeing the "social" aspect of corporate social responsibility as hampering its profit interests, they could be seen as an altruistic, socially, and ecologically oriented package that might rather improve the company's overall market position including their profit results. This will put heightened demands on such companies marketing and branding departments and efforts, so as to "sell" their combined responsibilities to their employees, stakeholders, customers, and the global business community; but the results should be worth it. After all, it is a business and marketing insight of our globalized world that "doing good" socially and ecologically means you will also "do well" economically. Being able to say so about your company and back it up with verifiable and transparent data such as the triple bottom line indicators should give any global tourism company's marketing and branding campaign a well-deserved and rewarding boost.

Altogether, the dynamics and interrelationships found within and between the travel forms of fast and slow tourism, as well as between these two travel forms and the triple bottom line, show a large potential for ongoing theoretical and practical development.

\section{References}

Brown, F. (2011). Tourism reassessed: Blight or blessing. Oxford: Butterworth-Heinemann.

Daley, B., \& Callum, T (2011). Challenges to growth: Environmental issues and the development of the air transport industry. In J. F. O'Connell, \& G. Williams (Eds.), Air transport in the 21 $1^{\text {st }}$ century: Key strategic developments (pp. 269294). Farnham: Ashgate.

Darcy, S., Cameron, B., \& Pegg, S. (2011). Developing a business case for accessible tourism. In D. Buhalis, \& S. Darcy (Eds.), Accessible tourism: Concepts and issues (pp. 241-259). Bristol, United Kingdom: Channel View Publications.

De Lara, R. A. A., \& Thöny, A. (2011). Responsible tourism in Asia. In G. Williams (Ed.), Responsible management in Asia: perspectives on CSR (pp. 146-160). Houndmills and New York: Palgrave Macmillan.

Dickinson, J., \& Lumsdon, L. (2010). Slow travel and tourism. London: Routledge.

Dickinson, J., \& Lumsdon, L. (2013). Slow travel. In A. Holden, \& D. Fennell (Eds.), The Routledge handbook of tourism and the environment (pp. 371-381). Oxon and New York: Routledge. 
Dwyer, L., \& Edwards, D. (2013). Ecotourism and the triple bottom line. In R. Ballantyne, \& J. Packer (Eds.), International handbook on ecotourism (pp. 245-263). Cheltenham and Northampton/Massachusetts: Edward Elgar Publishing.

Dwyer, L., Edwards, D., Mistills, N., Roman, C., Scott, N., \& Cooper, C. (2008). Megatrends underpinning tourism to 2020: Analysis of key drivers for change. Brisbane: Cooperative Research Centre for Sustainable Tourism.

Elkington, J. (1997). Cannibals with forks: The triple bottom line of $21^{\text {st }}$ century business. Oxford: Capstone Publishing.

Fullagar, S. (2012). Gendered cultures of slow travel: women's cycle touring as an alternative hedonism. In S. Fullagar, K. Markwell, \& E. Wilson (Eds.), Slow tourism: Experiences and mobilities (pp. 99-112). Bristol: Channel View Publications.

Fullagar, S., Wilson, E., \& Markwell, K. (2012). Starting slow: Thinking through mobilities and experiences. In S. Fullgar, K. Markwell, \& E. Wilson (Eds.), Slow tourism: Experiences and mobilities (pp. 1-8). Bristol: Channel View Publications.

Goeldner, C. R., \& Ritchie, J. R. B. (2014). Tourism: principles, practices, philosophies (12 ${ }^{\text {th }}$ ed.). Hoboken, J. N.: John Wiley \& Sons.

Graham, A. (2011). Key issues facing the airport industry. In J. F. O'Connell, \& G. Williams (Eds.), Air transport in the $21^{\text {st }}$ century (pp. 253-268). Farnham, UK, and Burlington, VT: Ashgate.

Gunesch, K. (2017a). Airline travel. In L. L. Lowry (Eds.), The SAGE international encyclopedia of travel and tourism, volume 1 (pp. 40-45). London, Thousand Oaks and New Delhi: Sage Publications.

Gunesch, K. (2017b). Business tourism. In L. L. Lowry (Eds.), The SAGE international encyclopedia of travel and tourism, volume 1 (pp. 198-201). London, Thousand Oaks and New Delhi: Sage Publications.

Gunesch, K. (2017c). International tourism. In L. L. Lowry (Eds.), The SAGE international encyclopedia of travel and tourism, volume 2 (pp. 668-671). London, Thousand Oaks and New Delhi: Sage Publications.

Gunesch, K. (2017d). International student travel. In L. L. Lowry (Eds.), The SAGE international encyclopedia of travel and tourism, volume 2 (pp. 661-668). London, Thousand Oaks and New Delhi: Sage Publications.

Gunesch, K. (2017e). Religion and tourism. In L. L. Lowry (Eds.), The SAGE international encyclopedia of travel and tourism, volume 3 (pp. 1012-1017). London, Thousand Oaks and New Delhi: Sage Publications.

Gunesch, K. (2017f). Slow tourism. In L.L. Lowry (Eds.), The SAGE international encyclopedia of travel and tourism, volume 3 (pp. 1118-1121). London, Thousand Oaks and New Delhi: Sage Publications.

Gunesch, K. (2017g). Travel and tourism's most pressing issues in the $21^{\text {st }}$ century 1 . In L. L. Lowry (Eds.), The SAGE international encyclopedia of travel and tourism, volume 4 (pp. 1307-1313). London, Thousand Oaks and New Delhi: Sage Publications.

Haessly, J. (2010). Tourism and a culture of peace. In O. Moufakkir, \& I. Kelly (Eds.), Tourism, progress and peace (pp. 116). Oxfordshire, UK: CABI.

Hall, D., \& Brown, F. (2010). Tourism and welfare: Ethics, responsibility and well-being. In S. Cole, \& N. Morgan (Eds.), Tourism and inequality: Problems and prospects (pp. 143-162). Wallingford, Oxfordshire: Cambridge.

Lück, M. (2012). Air transport. In P. Robinson (Eds.), Tourism: The key concepts (pp. 11-13). Oxford: Routledge.

Meyer, D. (2007). Pro-poor tourism: From leakages to linkages. A conceptual framework for creating linkages between the accommodation sector and 'poor neighbouring communities'. Current Issues in Tourism, 10(6), 558-583.

Moutinho, L., Ballantyne, R., \& Rate, S. (2011). The new business environment and trends in tourism. In L. Moutinho (Eds.), Strategic management in tourism (pp. 1-19). Cambridge: CABI.

Mu, Z., Li, H., Jian-Hong, W., Ji, L., Yan-Geng, J., \& Xiting, L. (2007). Religious tourism and cultural pilgrimage: A Chinese perspective. In R. Rai, \& N. D. Morpeth (Eds.), Religious tourism and pilgrimage festivals: An international perspective (pp. 98-112). Cambridge: CABI.

Murphy, P. (2012). Resort management and analysis: current and future directions. In C. H. C. Hsu, \& W. Gartner (Eds.), The Routledge handbook of tourism research (pp. 324-337). London, N.Y.: Routledge.

Olsen, D. H., \& Timothy, D. J. (2006). Tourism and religious journeys. In D. J. Timothy, \& D. H. Olsen (Eds.), Tourism, religion and spiritual journeys (pp. 1-22). Abingdon, UK: Routledge.

Page, S. J. (2009). Tourism management: Managing for change. Oxford, Burlington: Elsevier.

Richards, G. (2008). Youth travel matters: Understanding the global phenomenon of youth travel, Madrid: World Tourism Organization (WTO), \& World Youth Student and Educational Travel Confederation (WYSE).

Sharma, K. K. (2004). World tourism today. New Delhi, India: Sarup and Sons.

Stangel, L. (2014). Unraveling business travel: Collaboration technology can not only replace face-to-face get-togethers, but can improve upon them. Avaya Innovations Magazine, 1, 8-9. 
Tiyce, M., \& Wilson, E. (2012). Wandering Australia: Independent travellers and slow journeys through time and space. In S. Fullagar, K. Markwell, \& E. Wilson (Eds.), Slow tourism: Experiences and mobilities (pp. 113-127). Bristol, UK: Channel View Publications.

Tyrrell, T., C. M. Paris, \& Biaett, V. (2013). A quantified triple bottom line for tourism: experimental results. Journal of Travel Research, 52(3), 279-293.

United Nations Environment Program, \& World Tourism Organization (UNEP) (2005). Making tourism more sustainable: a guide for policy makers, Paris and Madrid: United Nations Environment Program, \& World Tourism Organization. 